\title{
Polysaccharide-modified nanoparticles with intelligent CD44 receptor targeting ability for gene delivery
}

This article was published in the following Dove Press journal: International Journal of Nanomedicine

\section{Wen Jen $\operatorname{Lin}^{1,2}$ \\ Wei Chi Lee'}

'School of Pharmacy, College of Medicine, National Taiwan University, Taipei, Taiwan; ${ }^{2}$ Drug Research Center, College of Medicine, National Taiwan University, Taipei, Taiwan
Correspondence: Wen Jen Lin School of Pharmacy, College of Medicine, National Taiwan University, 33 Linsen S Road, Taipei 10050, Taiwan

Tel +886233668765

Fax +88622391 9098

Email wjlin@ntu.edu.tw
Background: Hyaluronic acid (HA) and chondroitin sulfate (CD) are endogenous polysaccharides. In recent years, they have aroused the interest of scientists because of specific binding to CD44 receptors, which are overexpressed in several types of tumors.

Methods: In this study, HA- and CD-modified poly(D,L-lactide-co-glycolide)-poly(ethylene glycol) (PLGA-PEG) copolymers were synthesized and applied to encapsulate 1,2-Dioleoyl3-trimethylammonium-propane (DOTAP)/pDNA (D/P) lipoplex as CD44 receptor targeting gene delivery nanoparticles (NPs).

Results: The particle size of CD-PEG-PLGA-D/P $(186.8 \pm 21.7 \mathrm{~nm})$ was smaller than that of HA-PEG-PLGA-D/P $(270.2 \pm 13.8 \mathrm{~nm})$, with narrow size distribution, and both HA-PEGPLGA-D/P NPs and CD-PEG-PLGA NPs possessed negative zeta potentials $(-39.63 \pm 5.44 \mathrm{mV}$ and $-38.9 \pm 2.0 \mathrm{mV}$, respectively), which prevent erythrocytes from agglutination. Both NPs exhibited $\mathrm{pH}$-dependent release and had faster release in $\mathrm{pH} 4.0$ than in $\mathrm{pH} 7.4$. Generally, the CD-PEG-PLGA-D/P NPs possessed less cytotoxicity than HA-PEG-PLGA-D/P NPs. The D/Ploaded HA-PEG-PLGA and CD-PEG-PLGA NPs expressed significantly higher transfection in CD44 high-expressed U87 (30.1\% $\pm 2.1 \%$ and $40.7 \% \pm 4.3 \%$, respectively) than in CD44negative HepG2 $(3.3 \% \pm 1.5 \%$ and $1.4 \% \pm 1.0 \%$, respectively $)(p<0.001)$. It was revealed that the endocytosis of HA-PEG-PLGA-D/P NPs was majorly dominated by macropinocytosis and the endocytosis of CD-PEG-PLGA-D/P NPs was dominated by clathrin-mediated endocytosis pathway $(p<0.001)$.

Conclusion: The high selectivity to CD44-positive U87 cancer cells and low cytotoxicity in L929 normal cells assured the promising potential of CD-PEG-PLGA NPs as gene delivery nano-carriers.

Keywords: hyaluronic acid, chondroitin sulfate, poly(lactide-co-glycolide)

\section{Introduction}

Poly(D,L-lactide-co-glycolide)-poly(ethylene glycol) (PLGA-PEG) copolymeric nanoparticles (NPs) have been applied as drug and gene delivery nano-carriers with passive targeting character. ${ }^{1,2}$ The PLGA-PEG copolymeric NPs possess amphiphilic conformation comprising hydrophobic PLGA core for drug encapsulation and hydrophilic PEG shell to avoid the reticuloendothelial system recognition. ${ }^{3,4}$ These long-circulating NPs preferentially localize in the tumors from the leaky vasculature and the impaired lymphatic drainage due to enhanced permeability and retention effect. ${ }^{5}$ The NPs with specific targeting to cancer cells are designed by chemical conjugation of targeting ligands that recognize the specific high-expressed receptors on the cancer cell surface in order to improve therapeutic efficacy and reduce side effects..$^{6-9}$ The novel chemistry through smart 
design and synthesis develops polymer-based drug delivery systems for next-generation nanomedicine. ${ }^{10}$ Many advanced nanovehicles constructed by polymer and lipid-polymer have been developed and applied in combinational cancer therapy to achieve an effective therapeutic efficacy. ${ }^{11-14}$

The CD44 is a kind of type I transmembrane protein. It contains three domains: ectodomain, transmembrane domain, and intracellular domain. The variant form of CD44 (CD44v) contains variable exons and expresses in different types of cancer cells. ${ }^{15}$ Osteopontin (OPN) is a proinflammatory cytokine, and OPN C-terminal is formed from OPN cleaved by thrombin during inflammation. It can bind to CD44v6-7 receptors on cell surface and may be considered as a CD44 ligand. ${ }^{16,17}$ Hyaluronic acid (HA) and chondroitin sulfate (CD) are endogenous polysaccharides that exist in the extracellular matrix. In recent years, they have aroused much interest of scientists because of specific binding to CD44 receptors, which are overexpressed in several types of tumors. ${ }^{18} \mathrm{HA}$ is an anionic polysaccharide composed by glucuronic acid and $N$-acetyl-D-glucosamine linked by $\beta-1,3$ and $\beta-1,4$ glycosidic bond. $\mathrm{CD}$ is a linear polysaccharide composed of glucuronic acid and $N$-acetyl-D-galactosamine linked by $\beta-1,3$ and $\beta-1,4$ glycosidic linkage. It is the main component of connective tissues and chondrocytes. ${ }^{19}$

CD-based biomaterials are widely applied in tissue regeneration nowadays. On the other hand, some CD-based nanocarriers have been developed for anticancer therapy. Liu et al applied chondroitin-conjugated polycaprolactone micelle to encapsulate camptothecin; the $\mathrm{IC}_{50}$ was reduced by 60 -fold as compared to camptothecin-free drug in CD44-overexpressed CRL-5802 cells, and the tumor volume was inhibited by 3.8fold smaller than free drug in tumor-bearing mice. ${ }^{20}$ Gurav et al developed CD-coated gold NPs to overcome multidrug resistance of chemotherapeutic drug in human ovarian carcinoma, doxorubicin resistant, variant cell line. ${ }^{21} \mathrm{HA}$ is usually investigated and applied in drug delivery applications. Park et al used HA-conjugated ceramide to encapsulate doxorubicin for CD44 targeting purpose. ${ }^{22}$ The HA-based endosomal $\mathrm{pH}-$ activatable micelles successfully overcome low tumor-target efficiency and insufficient anticancer drug release at the target cells, and the paclitaxel-loaded micelles effectively inhibit tumor growth in CD44-overexpressed human breast cellbearing nude mice with a $100 \%$ survival rate over 55 days. ${ }^{23}$ The chemotherapy combined photothermal therapy has been demonstrated in HA grafting polyethylene glycol-modified hollow Prussian blue NPs. The NPs expressed efficient photothermal effect and targeting ability and induced synergetic effect against CD44 receptor-overexpressed Hela cancer cells. ${ }^{24}$ It is known that the skin permeation of HA increases with its decreasing molecular weight (MW) where the HA with MW 1,000-1,400 kDa, 100-300 kDa, and 20-50 kDa are localized in the stratum corneum, superficial layer of the epidermis, and epidermis layer of the skin, respectively. ${ }^{25}$

The effect of HA MW on cellular transfection of HAconjugated micelles has been elucidated in CD44-positive MCF-7 cells previously. ${ }^{26}$ The high-MW HA-conjugated micelles showed prominently higher protein expression than low-MW HA-conjugated micelles. In this study, two kinds of polysaccharides, CD and HA, possessing CD44 receptorbinding affinity were selected to chemically conjugate with PLGA-PEG copolymers as specific targeting ligands. The effects of polysaccharide type on NP biocompatibility, stability, DNA release, cytotoxicity, and cellular transfection were investigated. Finally, the endocytosis mechanism of polysaccharide-conjugated PLGA-PEG NPs was evaluated.

\section{Materials and methods Materials}

Poly(lactide-co-glycolide) (PLGA 50:50, RG 503H) was purchased from Evonik Corporation Birmingham Laboratories (Birmingham, AL, USA). Poly(ethylene glycol) bis(amine) (PEG diamine, 5,000 Da) was from Laysan Bio Inc. (Arab, AL, USA). Sodium hyaluronate (120 kDa) was from Long Chen Shing Trading Co., Ltd. (Kaohsiung, Taiwan). CD (122 kDa) was from San Ho Shing Co. Ltd. (Taiwan). Plasmid encoding enhanced green fluorescent protein ( $p$ EGFP-N1) was kindly provided by Dr Jin Long Chen from National Defense Medical Center in Taiwan. 1,2Dioleoyl-3-trimethylammonium-propane (DOTAP) was from Avanti Polar Lipids, Inc. (Alabaster, AL, USA). L929 mouse fibroblast cell line (ATCC ${ }^{\circledR} \mathrm{CCL}-1^{\mathrm{TM}}$ ) was from Bioresource Collection and Research Center (Hsinchu, Taiwan). U87 human glioblastoma cell line was provided by Professor JuiChang Tsai (National Taiwan University, Taipei, Taiwan), and the HepG2 cancer cell line was provided by Dr Hui-Lin Wu (Hepatitis Research Center, National Taiwan University Hospital, Taiwan). This research and use of the gifted cell lines were approved by an institutional review board of the National Taiwan University.

\section{Synthesis and characterization of HA-PEG-PLGA and CD-PEG-PLGA copolymers}

The PLGA-PEG copolymer was synthesized based on previously published method. ${ }^{27,28}$ The composition of synthesized PLGA-PEG copolymer has been confirmed by proton nuclear magnetic resonance ( $\left.{ }^{1} \mathrm{H}-\mathrm{NMR}\right)$ at $\delta 5.2 \mathrm{ppm}$ and $\delta 1.5 \mathrm{ppm}$ for $\mathrm{CH}$ and $\mathrm{CH}_{3}$ of lactide, at $\delta 4.8$ ppm for $\mathrm{CH}_{2}$ of glycolide, and 
at $\delta 3.6 \mathrm{ppm}$ for $\mathrm{CH}_{2}$ of ethylene glycol. The PLGA-PEG copolymer was further conjugated with $\mathrm{HA}$ or $\mathrm{CD}$ at a feed molar ratio of 1:1. PLGA-PEG was dissolved in dimethyl sulfoxide (DMSO), which was slowly added into HA or CD aqueous solution. Sodium cyanoborohydride $\left(\mathrm{NaBH}_{3} \mathrm{CN}\right)$ and N,Ndiisopropylethylamine (DIPEA) were added as the reducing agent and the catalyst, respectively. The reaction was performed at room temperature for 48 hours followed by dialysis. The dialyzed suspension was centrifuged under $17,000 \mathrm{rpm}$ at $4^{\circ} \mathrm{C}$ for $30 \mathrm{~min}$ and then freeze dried. The obtained HA-PEG-PLGA and CD-PEG-PLGA copolymers were identified by ${ }^{1} \mathrm{H}-\mathrm{NMR}$.

\section{Preparation and characterization of D/P loaded NPs}

The DOTAP/pDNA (D/P) lipoplex at a weight ratio 5:1 was prepared where the DNA aqueous solution $(80 \mu \mathrm{g} / \mathrm{mL}$, $500 \mu \mathrm{L})$ was added into DOTAP/DMSO $(400 \mu \mathrm{g} / \mathrm{mL}$, $500 \mu \mathrm{L}$ ) under vortex at $100 \mathrm{rpm}$ for $3 \mathrm{~min}$ and equilibrium for $30 \mathrm{~min}$ followed by dialysis. The D/P lipoplex was then encapsulated by NPs. Each copolymer was weighed and dissolved in water/DMSO (1:9 by volume) with a concentration of $1.6 \mathrm{mg} / \mathrm{mL}$. Equal volume of $\mathrm{D} / \mathrm{P}$ aqueous solution was added and mixed well followed by centrifugation. The D/P-loaded HA-PEG-PLGA and CD-PEG-PLGA NPs were obtained, which contained the same molar ratio of polymer to $p$ DNA at 40:1 by weight. The particle size and zeta potential were measured by Nano-ZS90 Zetasizer (Malvern Instruments LTD., Worcestershire, UK) at $90^{\circ}$ scattering angle detection. The amount of DNA loaded in NPs was determined after centrifugation. The supernatant was collected and quantified using PicoGreen reagent. The amount of DNA loaded in NPs was calculated by subtracting the amount of DNA in the supernatant from the amount of DNA added. For gel retardation study, the naked $p \mathrm{DNA}, \mathrm{D} / \mathrm{P}$ lipoplex, HA-PEGPLGA-D/P, and CD-PEG-PLGA-D/P were mixed with $6 \times$ DNA loading dye before being loaded onto $0.8 \%$ agarose gel containing $0.05 \%$ ethidium bromide. The gel electrophoresis was performed at $50 \mathrm{~V}$ for $90 \mathrm{~min}$, and the image was collected using imaging system (UVP BioDoc-It ${ }^{\circledR} 220$ Imaging System; Ultra-Violet Products Ltd., San Jose, CA, USA) at UV $302 \mathrm{~nm}$. For agglutination study, the NPs were mixed with erythrocytes at $37^{\circ} \mathrm{C}$ for $15 \mathrm{~min}$ and subsequently observed using an optical microscope with $800 \times$ magnification. The stability of D/P-loaded NPs was evaluated by their particle size change during storage at $4^{\circ} \mathrm{C}$ for 28 days.

\section{In vitro release study}

The D/P-loaded NPs were suspended in $1 \mathrm{~mL}$ pH 7.4 phosphate-buffered solution or $\mathrm{pH} 4.0$ acetate buffered solution containing $500 \mathrm{U}$ lipase in the dialysis bag (cutoff molecular weight $12,000-14,000 \mathrm{Da}$ ). It was placed in a $50 \mathrm{~mL}$ tube containing $20 \mathrm{~mL}$ of the same release medium and stirred under $100 \mathrm{rpm}$ at $37^{\circ} \mathrm{C}$. The $0.2 \mathrm{~mL}$ medium was withdrawn at each specific time interval and was replaced with the same volume of fresh release medium. The concentration of DNA in each sample was determined using PicoGreen reagent. The cumulative amount of DNA released at each sampling point was corrected for the volume of the release medium. The release kinetics of DNA from NPs was evaluated based on zero-order, first-order, Higuchi's square root, and Hixson-Crowell models, and the release rate constant was determined.

\section{Cytotoxicity of DNA-loaded NPs}

The cytotoxicity of D/P-loaded NPs was assessed in CD44-positive U87 cancer cells, CD44-negative HepG2 cancer cells, and L929 normal cells. Three cell lines were seeded in 96-well plates and incubated at $37^{\circ} \mathrm{C}$ for 24 hours. The D/Ploaded NPs and lipofectamine containing the same amount of DNA (800 ng) were added and incubated for additional 24 hours. The medium was removed, and MTT solution was added and incubated at $37^{\circ} \mathrm{C}$ for 4 hours. The resulting formazan was solubilized in dimethyl sulfoxide, and the absorbance was measured using an enzyme-linked immunosorbent assay reader (Power Wave XS; BioTek, Winooski, VT, USA) at $570 \mathrm{~nm}$.

\section{Transfection study}

The transfection study was performed in L929 normal cells, CD44-positive U87 cells, and CD44-negative HepG2 cells. The cells were seeded in 6-well plates at a density of $2 \times 10^{5}$ cells/well for 24 hours. The naked $p$ DNA and $\mathrm{D} / \mathrm{P}$-loaded NPs in cultured medium were added and incubated for 12 hours. After that the medium was removed, and fresh medium containing fetal bovine serum was added and incubated for additional 48 hours. The cells were washed with phosphate-buffered solution and harvested by trypsin followed by suspension in phosphate-buffered solution. The green fluorescence produced by expression of $p$ DNA in the cells was measured by flow cytometer (Becton Dickinson, Franklin Lakes, NJ, USA) at an excitation wavelength of $488 \mathrm{~nm}$ and an emission wavelength of $530 \mathrm{~nm}$. In total, 10,000 cells were analyzed for each sample, and the upper limit of background fluorescence was set no more than $1 \%$.

\section{Endocytosis mechanism}

The CD44-positive U87 cells were seeded in 6-well plates at a density of $2 \times 10^{5}$ cells/well for $24 \mathrm{~h}$. The cells were pre-treated by chlorpromazine (a clathrin-mediated endocytosis inhibitor), 
nystatin (a caveolin-mediated endocytosis inhibitor), and amiloride (a macropinocytosis inhibitor), respectively, for 30 min followed by incubation with D/P-loaded HA-PEG-PLGA and CD-PEG-PLGA NPs for additional 12 hours. After that the medium was removed, and the cells were washed with phosphate-buffered solution and incubated with fetal serum medium for $48 \mathrm{~h}$. The cells were harvested by trypsin followed by suspension in phosphate-buffered solution for flow cytometry analysis as mentioned previously.

\section{Statistical analysis}

The data were expressed as mean \pm standard deviation. Statistical analysis was performed via one-way analysis of variance test and Student's $t$-test using SigmaPlot 12.5, and a value for $p<0.05$ was considered statistically significant.

\section{Results and discussion \\ Characterization of D/P-loaded NPs}

The HA- and CD-conjugated PLGA-PEG copolymers were synthesized (Scheme 1A) and confirmed by ${ }^{1} \mathrm{H}-\mathrm{NMR}$ (Figure 1) before NP preparation. The peak at 1.9-2.1 ppm was assigned to $-\mathrm{CH}_{3}$ protons of $\mathrm{HA}$ and $\mathrm{CD}$, peak at 1.2-1.4 ppm was assigned to $-\mathrm{CH}_{3}$ of glycolide, and the peak at 3.6-3.8 ppm was assigned to the $-\mathrm{CH}_{2}-\mathrm{CH}_{2}-\mathrm{O}-$ protons of $\mathrm{PEG}$ repeat units. The D/P lipoplex with a weight ratio of 5:1 was encapsulated by HA-PEG-PLGA and CD-PEG-PLGA NPs as illustrated in Scheme 1B, and the corresponding DNA encapsulation efficiency was $97.2 \% \pm 1.8 \%$ and $80.8 \% \pm 14.5 \%$, respectively. Figure $2 \mathrm{~A}$ and $\mathrm{B}$ illustrate the mean particle size and zeta potential of D/P lipoplex and D/P-loaded NPs. With regard to the characteristics of D/P 5:1 lipoplex, the particle size was $169.5 \pm 11.6 \mathrm{~nm}$ with polydispersity index (PDI) of $0.20 \pm 0.02$, the zeta potential was $24.0 \pm 5.6 \mathrm{mV}$, and the complex efficiency was $98.1 \% \pm 2.2 \%$. The particle size of CD-PEG-PLGA-D/P $(186.8 \pm 21.7 \mathrm{~nm})$ was smaller than that of HA-PEG-PLGA-D/P $(270.2 \pm 13.8 \mathrm{~nm})$. All NPs had narrow size distribution with PDI $<0.25$. Herein, the HA- and CD-PEG-PLGA NPs possessed negative zeta potential $(-39.63 \pm 5.44 \mathrm{mV}$ vs $-38.9 \pm 2.0 \mathrm{mV})$ due to bearing carboxylic acid groups. Figure $2 \mathrm{C}$ illustrates the gel electrophoresis of D/P lipoplex, HA-PEG-PLGA-D/P, and CD-PEG-PLGA-D/P in the presence of external electric field. The result showed that no DNA was released from vectors, which indicated that DOTAP efficiently complexed with DNA and retarded DNA in NPs. These NPs were further tested for their biocompatibility via an agglutination study of erythrocytes. Figure 3 shows the morphology of erythrocytes before and after incubation with HA- and CD-PEG-PLGA-D/P NPs,

A

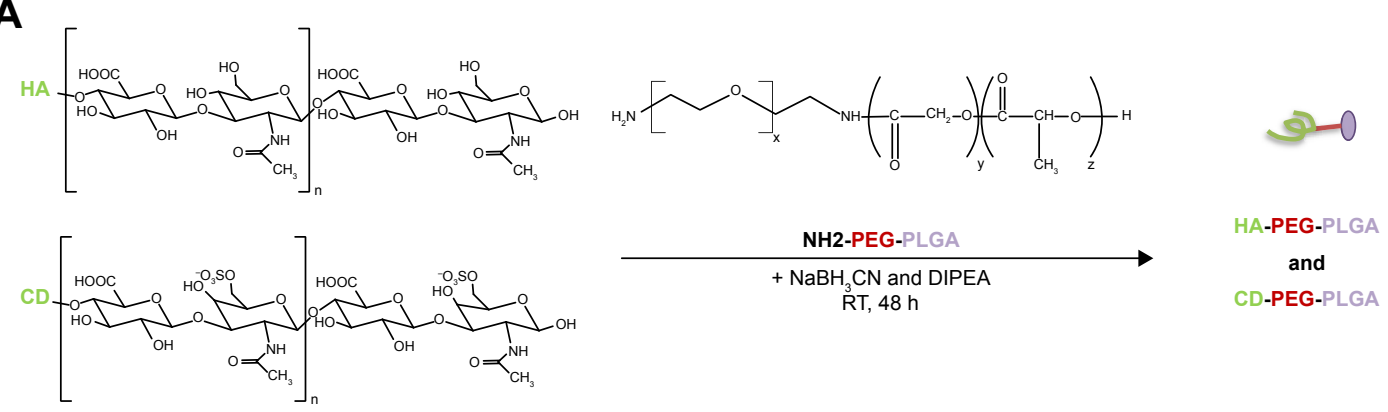

B

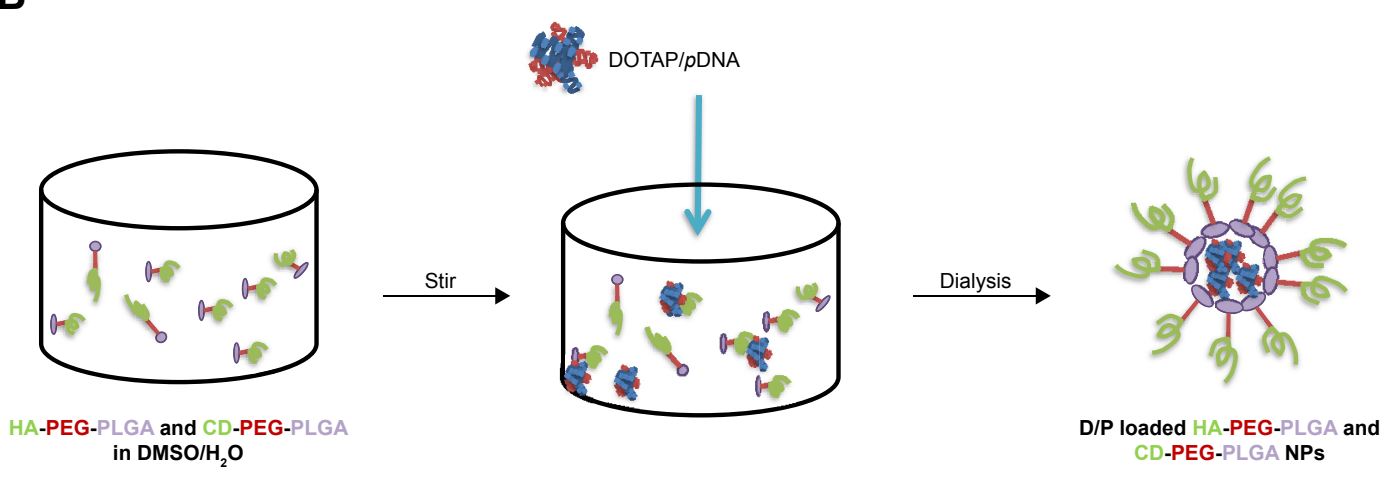

Scheme I (A) Synthesis of HA-PEG-PLGA and CD-PEG-PLGA copolymers. (B) Preparation of D/P-loaded NPs.

Abbreviations: CD, chondroitin sulfate; DIPEA, N,N-diisopropylethlamine; DOTAP, I,2-dioleoyl-3-trimethylammonium-propane; D/P, I,2-dioleoyl-3-trimethylammoniumpropane/pDNA; HA, hyaluronic acid; $\mathrm{NaBH}_{3} \mathrm{CN}$, sodium cyanoborohydride; NPs, nanoparticles; PEG, poly(ethylene glycol); PLGA, poly(D,L-lactide-co-glycolide); RT, room temperature. 


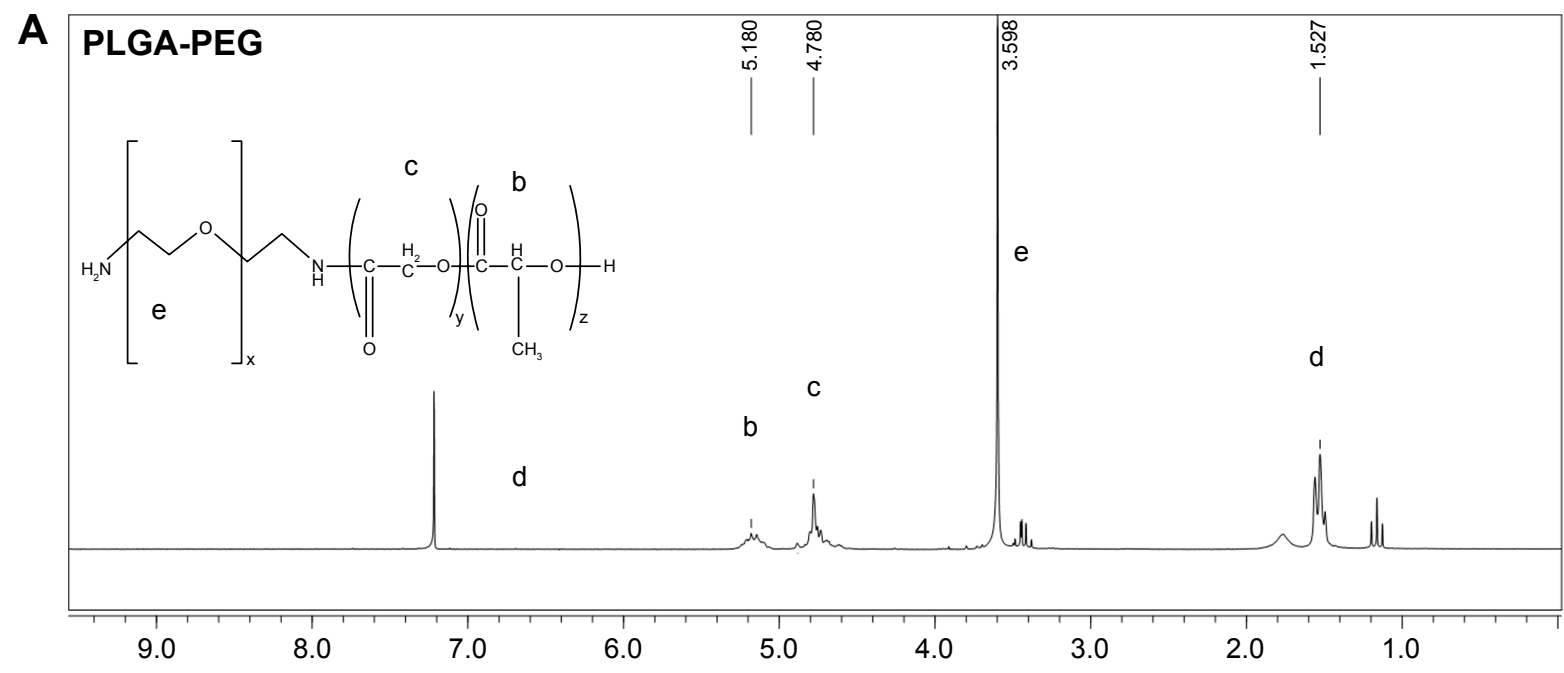
ppm

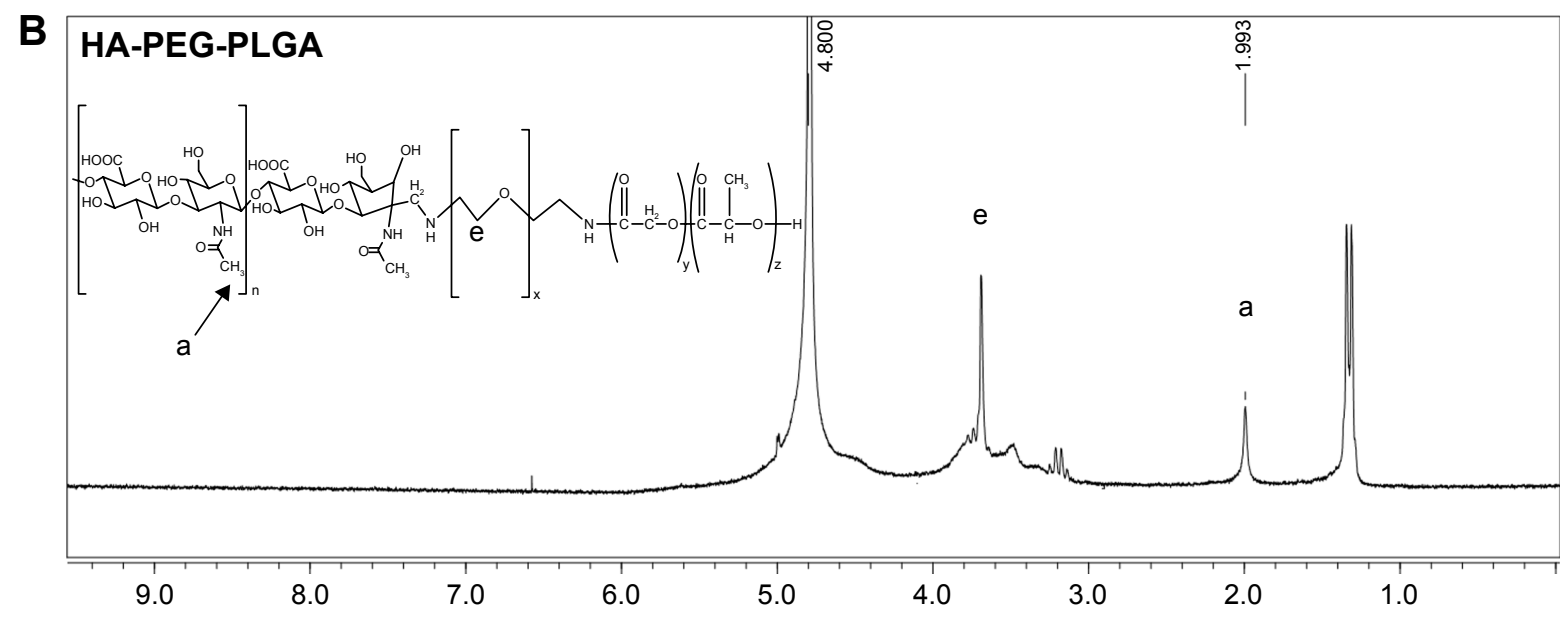
ppm

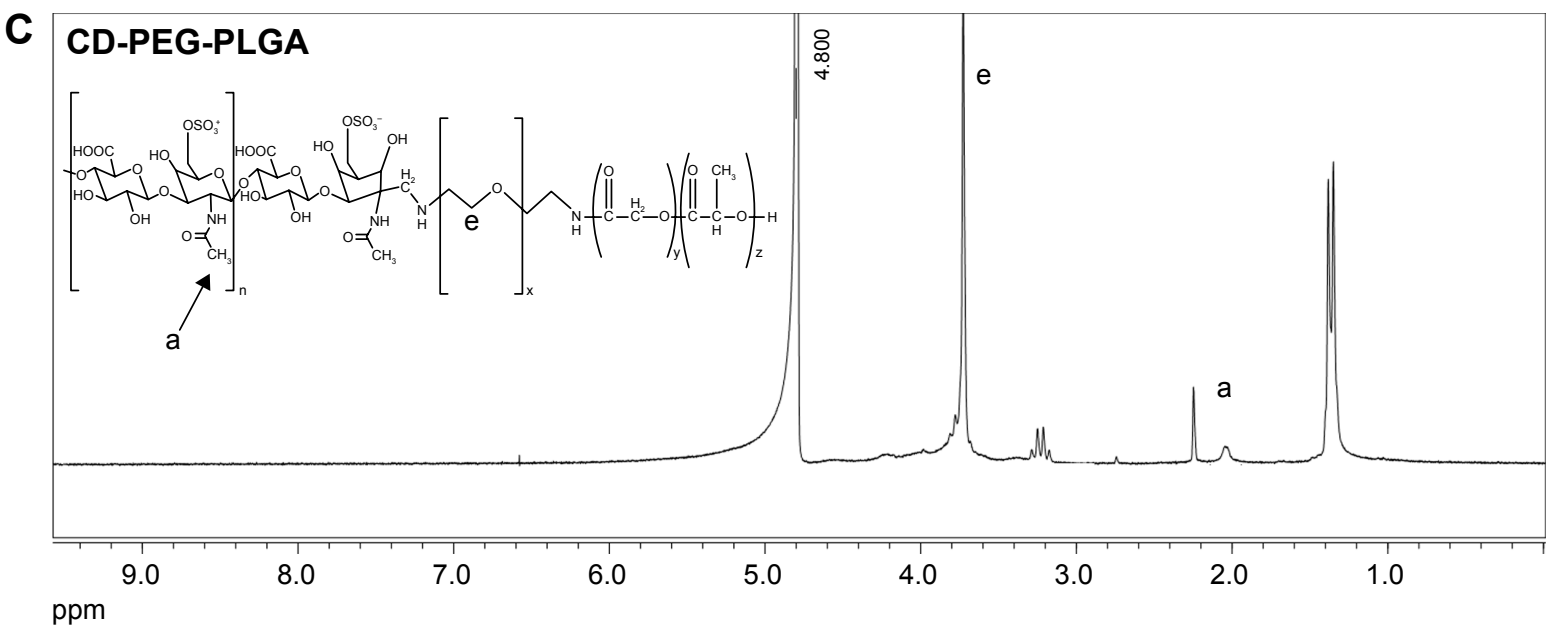

Figure I The 'H-NMR spectra of (A) PLGA-PEG, (B) HA-PEG-PLGA, and (C) CD-PEG-PLGA copolymers.

Abbreviations: 'H-NMR, proton nuclear magnetic resonance; $C D$, chondroitin sulfate; HA, hyaluronic acid; PEG, poly(ethylene glycol); PLGA, poly(D,L-lactide-co-glycolide).

respectively. It was clearly illustrated that no erythrocyte agglutination occurred. Both negative-charged character and PEGylation of these NPs avoided erythrocyte agglutination and maintained erythrocyte morphology.

\section{Stability of D/P-loaded NPs}

Figure 4 shows the particle size and PDI of D/P-loaded NPs during storage at $4^{\circ} \mathrm{C}$ for 28 days. The HA-PLGA-PEG and CD-PLGA-PEG NPs maintained their particle size in the 

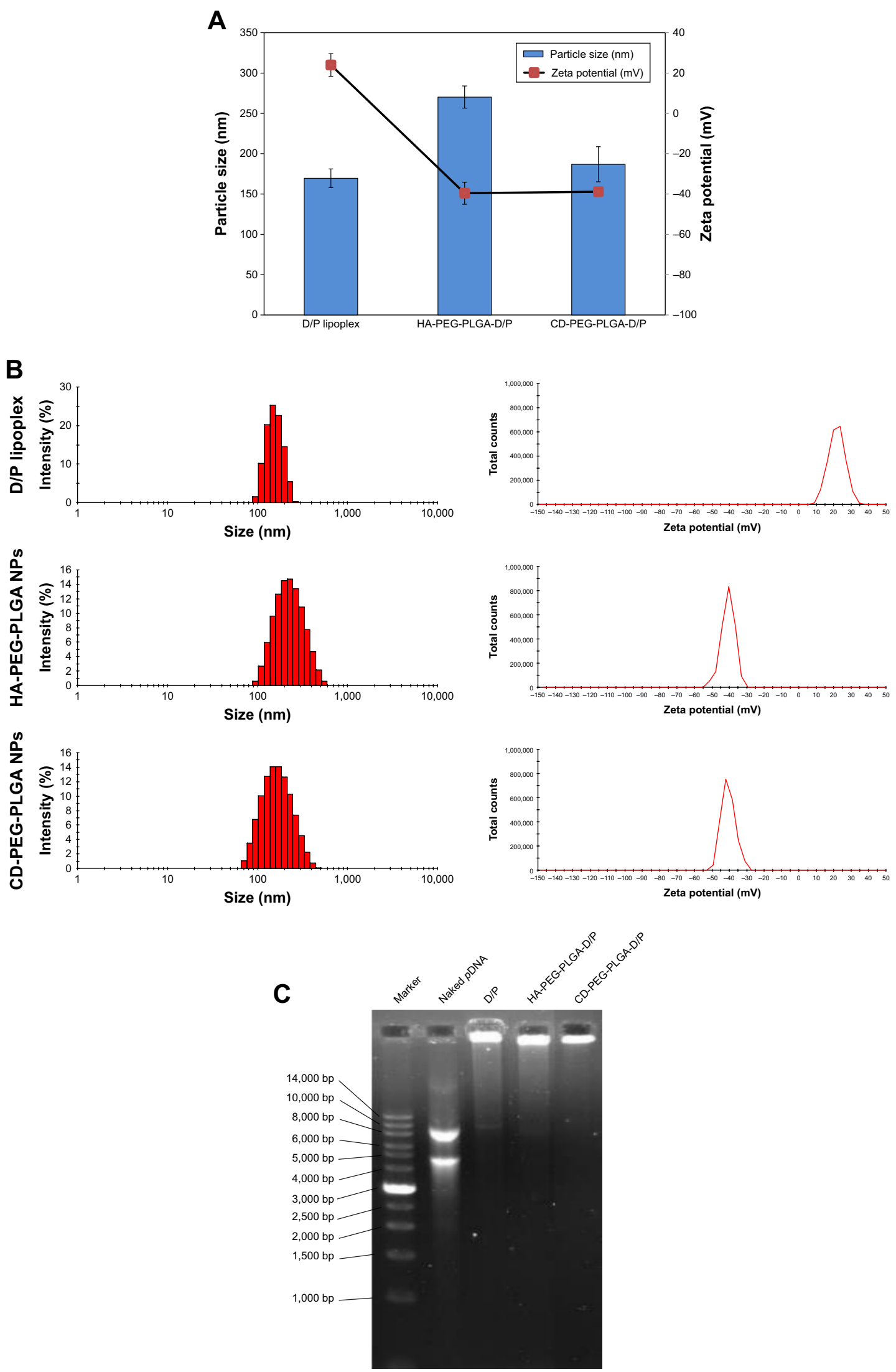

Figure 2 Particle size, zeta potential, and gel electrophoresis of D/P lipoplex and D/P-loaded HA-PEG-PLGA and CD-PEG-PLGA NPs.

Notes: (A) Mean particle size and mean zeta potential $(n=3)$. (B) Size and zeta potential distribution. (C) Gel electrophoresis at $50 \mathrm{~V}$ for 90 min.

Abbreviations: CD, chondroitin sulfate; D/P, I,2-dioleoyl-3-trimethylammonium-propane/pDNA; HA, hyaluronic acid; NPs, nanoparticles; PEG, poly(ethylene glycol); PLGA, poly(D,L-lactide-co-glycolide). 

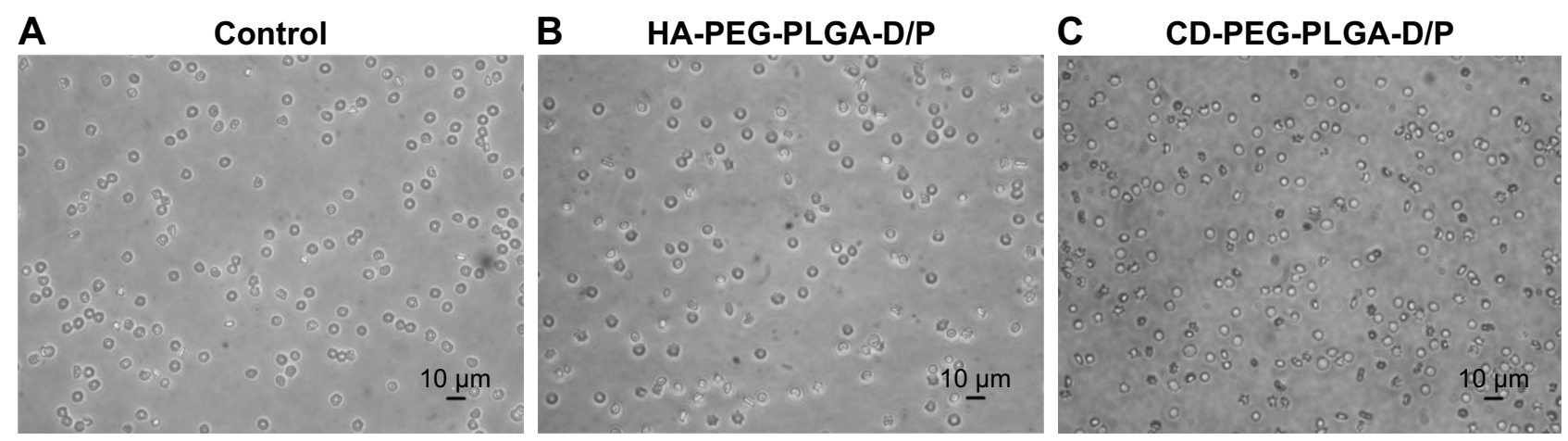

Figure 3 The morphology of erythrocytes (A) before and after being incubated with (B) D/P-loaded HA-PEG-PLGA and (C) D/P-loaded CD-PEG-PLGA NPs, respectively.

Abbreviations: CD, chondroitin sulfate; D/P, I,2-dioleoyl-3-trimethylammonium-propane/pDNA; HA, hyaluronic acid; NPs, nanoparticles; PEG, poly(ethylene glycol); PLGA, poly(D,L-lactide-co-glycolide).

range of $96.8 \%-105.9 \%$ and $92.5 \%-103.0 \%$, respectively, relative to the freshly prepared NPs, and the PDI values remained $<0.26$, which indicated that no severe aggregation or dissociation occurred. It seemed that the hydrophilic PEG and charged polysaccharides play important roles in maintaining NP stability via surrounding the outer shell of the NPs to exert shielding and electrostatic effects.

\section{In vitro release}

Figure 5 illustrates the release of DNA from HA-PEG-PLGA and CD-PEG-PLGA NPs in pH 7.4 and pH 4.0 (500 U lipase) release media. Both NPs exhibited sustained release behavior with similar release pattern. Herein, the DNA was completely released in $\mathrm{pH} 4.0$ release medium within 24 hours but sustained release up to 72 hours in $\mathrm{pH} 7.4$ release medium. PLGA is a kind of polyester and degraded by enzymatic hydrolysis especially in an acidic condition, which results in DNA release in $\mathrm{pH} 4.0$ release medium faster than in $\mathrm{pH} 7.4$ release medium. This $\mathrm{pH}$-dependent release character favored

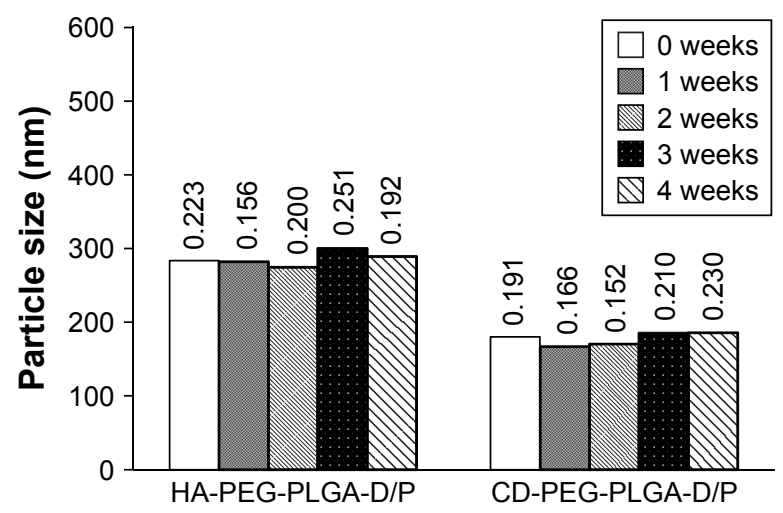

Figure 4 Particle size and PDI of D/P-loaded HA-PEG-PLGA and CD-PEG-PLGA NPs stored at $4^{\circ} \mathrm{C}$ for 4 weeks.

Abbreviations: $C D$, chondroitin sulfate; D/P, I,2-dioleoyl-3-trimethylammoniumpropane/pDNA; HA, hyaluronic acid; NPs, nanoparticles; PDI, polydispersity index; PEG, poly(ethylene glycol); PLGA, poly(D,L-lactide-co-glycolide).
DNA release after NP endocytosis into cells. The release kinetics of DNA from NPs was further elucidated. The result showed that the release of DNA in $\mathrm{pH} 7.4$ release medium was best fitted by Higuchi model indicating diffusion-dominated release. The corresponding release rate constants $\left(k_{h}\right)$ of HA-PEG-PLGA-D/P and CD-PEG-PLGA-D/P NPs were $8.56 \% \pm 1.65 \% \mathrm{~h}^{-1 / 2}\left(r^{2}=0.980 \pm 0.010\right)$ and $10.19 \% \pm 2.07 \%$ $\mathrm{h}^{-1 / 2}\left(r^{2}=0.944 \pm 0.027\right)$, respectively. On the other hand, the release of DNA in $\mathrm{pH} 4.0$ acidic medium was best fitted by first-order release model in terms of DNA concentrationdependent release, and the corresponding release rate constants $\left(k_{1}\right)$ of HA-PEG-PLGA-D/P and CD-PEG-PLGA-D/P were $0.136 \% \pm 0.030 \% \mathrm{~h}^{-1}\left(r^{2}=0.967 \pm 0.031\right)$ and $0.140 \% \pm$ $0.065 \% \mathrm{~h}^{-1}\left(r^{2}=0.905 \pm 0.112\right)$, respectively.

\section{Cytotoxicity of D/P-loaded NPs}

The CD44 receptor expression levels of U87 and HepG2 cell lines were determined by using anti-CD44 monoclonal antibody, and the corresponding expression values were $99.99 \%$ and $1.06 \%$, respectively (Figure 6A). This result confirmed that U87 is a CD44 high-expressed cancer cell line and HepG2 is a CD44-negative cancer cell line. The cytotoxicity of D/P-loaded HA-PEG-PLGA and CD-PEGPLGA NPs was then investigated in CD44-positive U87 and CD44-negative HepG2 cancer cell lines and L929 normal cell line for 24 hours. Figure 6B illustrates that the HA- and CD-PEG-PLGA NPs had much higher cellular viability than lipofectamine in these cell lines, and there was only $8.6 \% \pm 0.7 \%$ of viable cells left in L929 normal cells after being treated with lipofectamine. The CD-PEG-PLGA-D/P NPs had cellular viability similar to HA-PEG-PLGA-D/P NPs in U87 cells ( $78.03 \% \pm 8.39 \%$ vs $83.13 \% \pm 6.82 \%)$ but significantly higher than HA-PEG-PLGA-D/P NPs in HepG2 cells $(98.27 \% \pm 6.82 \%$ vs $60.13 \% \pm 3.35 \%, p<0.001)$. 


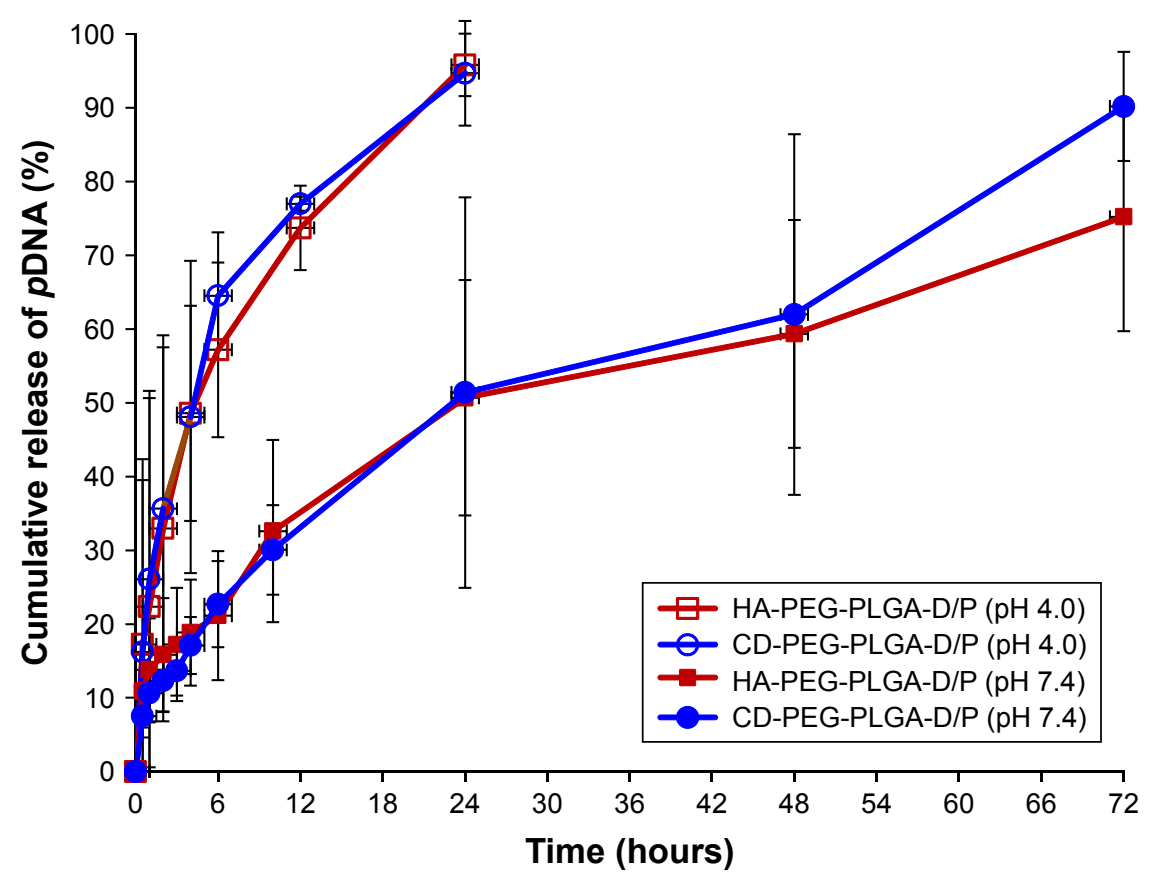

Figure 5 In vitro release of DNA from D/P-loaded HA-PEG-PLGA and CD-PEG-PLGA NPs in pH 7.4 and pH 4.0 (500 U lipase) release media (n=3). Abbreviations: CD, chondroitin sulfate; D/P, I,2-dioleoyl-3-trimethylammonium-propane/pDNA; HA, hyaluronic acid; NPs, nanoparticles; PEG, poly(ethylene glycol); PLGA, poly(D,L-lactide-co-glycolide).

The viability in L929 normal cells relative to U87 cancer cells was further calculated by equation (1), and the corresponding values of HA-PEG-PLGA-D/P and CD-PEG-PLGA-D/P NPs were 0.99 and 1.45 , respectively, which were much higher than that of lipofectamine 0.23 . The larger relative viability value indicated less cytotoxicity in normal cells than in cancer cells. In other words, the cellular viability of CD-PEG-PLGA$\mathrm{D} / \mathrm{P}$ NPs in normal cells was higher than in cancer cells. Oppositely, the cytotoxicity of lipofectamine in normal cells was much higher than in cancer cells in terms of low cellular viability in normal cells as compared to cancer cells.

$$
\text { Relative viability }=\frac{\text { Viability in normal cell line }}{\text { Viability in cancer cell line }}
$$

\section{Cellular transfection of DNA-loaded NPs}

Figure 7A and B illustrates the cellular transfection of D/P lipoplex, D/P-loaded HA-PEG-PLGA as well as CD-PEGPLGA NPs, and lipofectamine in CD44-positive U87 and CD44-negative HepG2 cell lines for 12 h. The HA-PEGPLGA-D/P and CD-PEG-PLGA-D/P NPs expressed significantly higher transfection in CD44 high-expressed U87 (30.1\% $\pm 2.1 \%$ vs $40.7 \% \pm 4.3 \%$ gated) than in CD44-negative HepG2 $(3.3 \% \pm 1.5 \%$ vs $1.4 \% \pm 1.0 \%$ gated $)(p<0.001)$. This result revealed that the polysaccharide-modified NPs were able to internalize into CD44 high-expressed U87 cells to produce EGF protein expression. Figure $7 \mathrm{C}$ shows the confocal microscopic images of intracellular uptake of NPs in U87 cells. The relative transfection of HA-PEG-PLGA-D/P and CD-PEG-PLGA-D/P NPs in CD44-positive U87 cells relative to CD44-negative HepG2 cells was calculated by equation (2), and the corresponding values were 9.2 and 30.1, respectively, which were much higher than lipofectamine 3.0. In other words, the transfection of HA-PEG-PLGA-D/P and CD-PEG-PLGA-D/P NPs in CD44-positive U87 cells was at least ninefold higher than in CD44-negative HepG2 cells. However, there was only threefold difference in EGF protein expression between CD44-positive and CD44-negative cells by lipofectamine. This result implied that the selectivity of NPs between CD44-positive and CD44-negative cancer cells was in the order of CD-PEG-PLGA-D/P > HA-PEG-PLGA$\mathrm{D} / \mathrm{P}>$ lipofectamine. Both polysaccharide-conjugated NPs possessed higher selectivity in CD44-positive and CD44negative cells than lipofectamine, although lipofectamine expressed higher transfection efficiency than NPs in CD44positive U87 cells. Herein, the CD-PEG-PLGA-D/P NPs possessed higher selectivity than HA-PEG-PLGA NPs. The $\mathrm{CD}$ acted as the targeting moiety to specifically bind to CD44 receptors resulting in efficient uptake of CD-conjugated NPs 

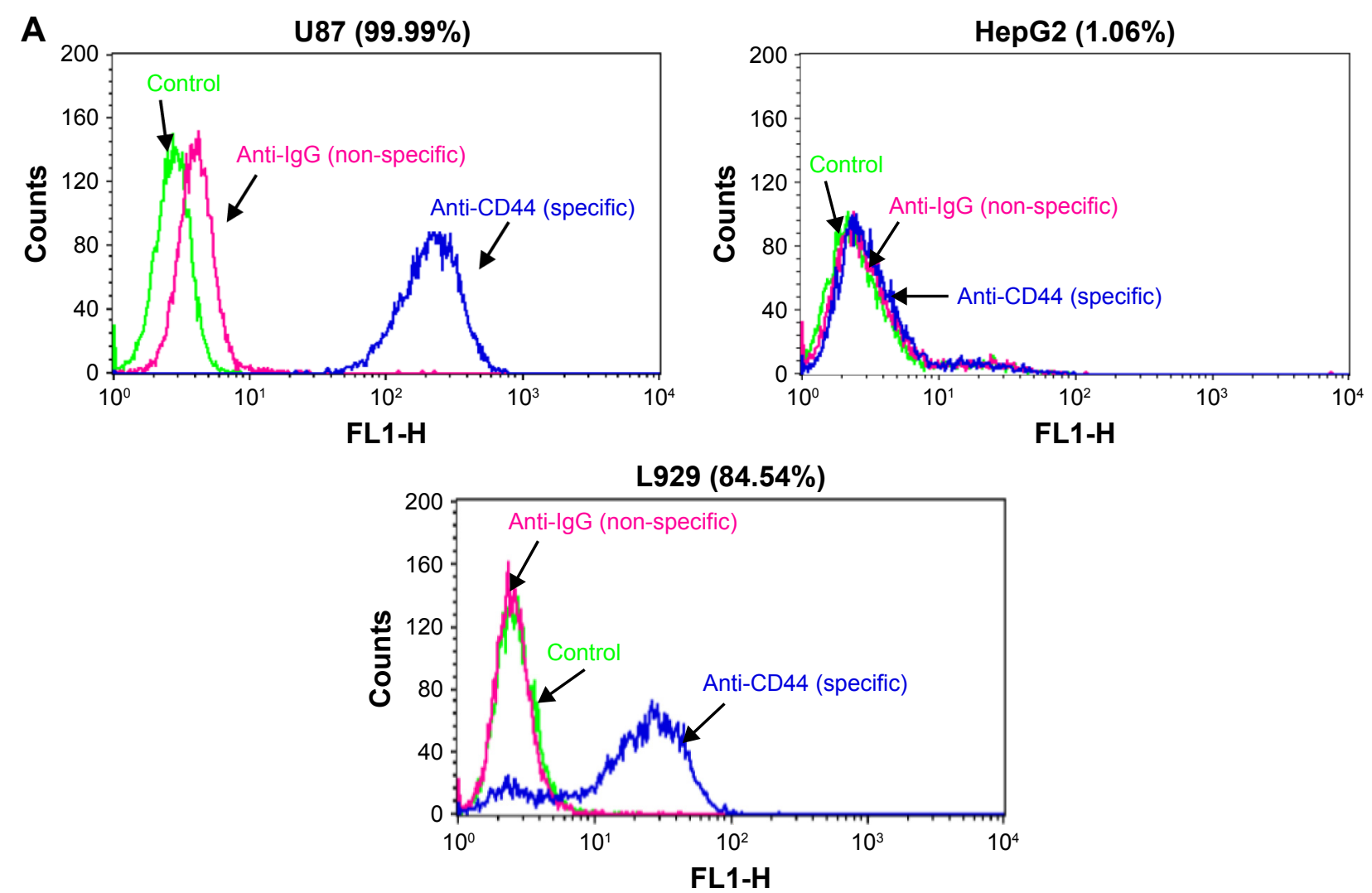

B

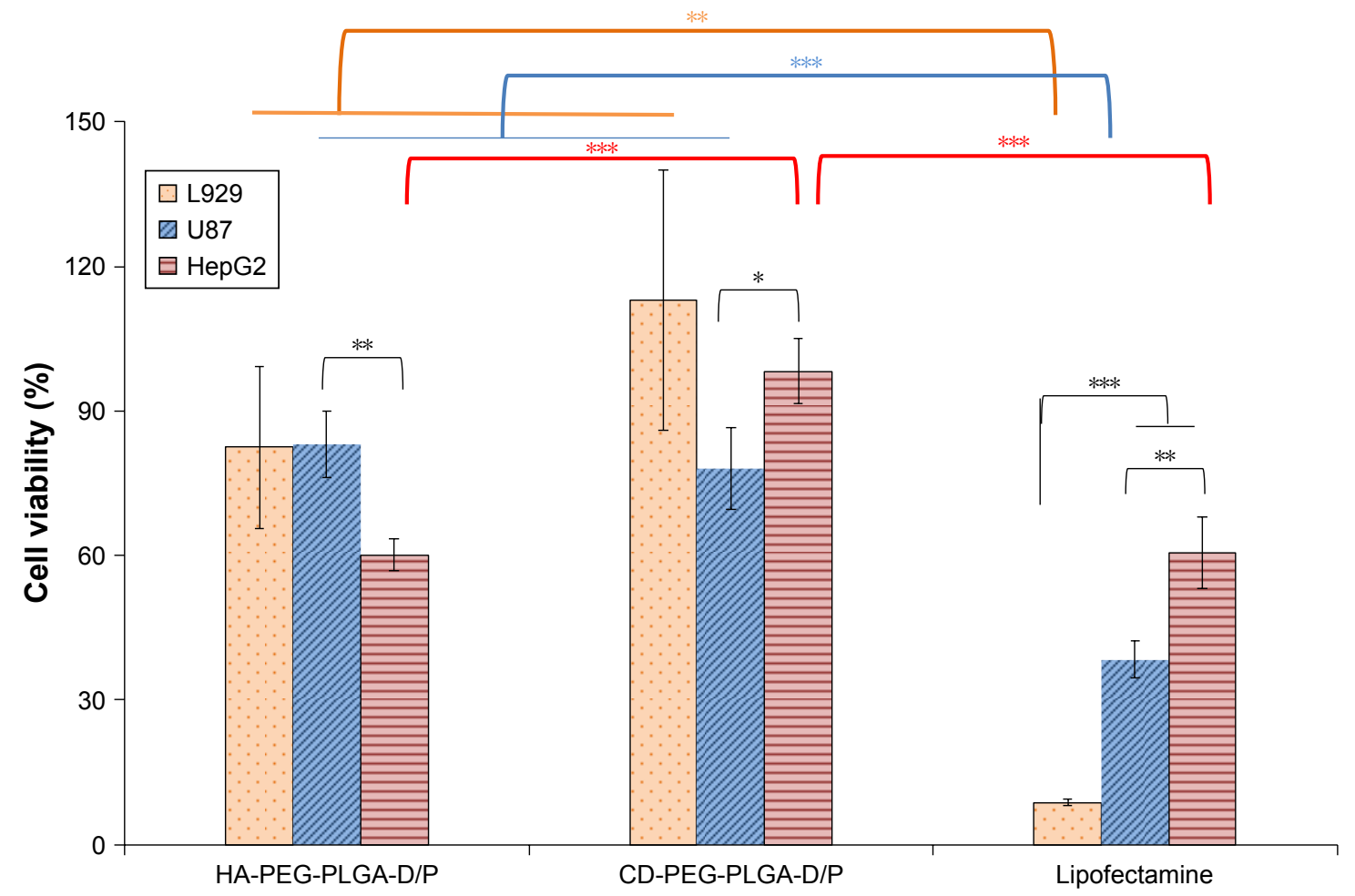

Figure 6 CD44 receptor expression levels and cellular viability of NPs.

Notes: (A) CD44 receptor expression levels (\%) on U87, HepG2, and L929 cell surface. (B) The cellular viability of L929, U87, and HepG2 after being incubated with D/P-loaded HA-PEG-PLGA and CD-PEG-PLGA NPs and lipofectamine for 24 hours $(n=3, * p<0.05$, ** $p<0.01$, *** $p<0.00 \mathrm{I})$.

Abbreviations: CD, chondroitin sulfate; D/P, I,2-dioleoyl-3-trimethylammonium-propane/pDNA; HA, hyaluronic acid; NPs, nanoparticles; PEG, poly(ethylene glycol); PLGA, poly(D,L-lactide-co-glycolide). 
and enhancing prominent transfection efficiency in CD44positive cells.

$$
\begin{aligned}
& \text { Relative transfection }_{\mathrm{CD} 44+/ \mathrm{CD} 44-} \\
& =\frac{\text { Transfection in CD44-positive U87 }_{\text {Transfection in CD44-negative HepG2 }}}{}
\end{aligned}
$$

\section{Endocytosis mechanism}

Figure 8 illustrates the transfection of HA-PEG-PLGA-D/P and CD-PEG-PLGA-D/P NPs in CD44-positive U87 cells after being pre-treated by chlorpromazine (a clathrin-mediated endocytosis inhibitor), nystatin (a caveolin-mediated endocytosis inhibitor), and amiloride (a macropinocytosis inhibitor), respectively. The result revealed that the endocytosis of HA-PEG-PLGA-D/P NPs was majorly dominated by macropinocytosis $(p<0.001)$, and the endocytosis of CDPEG-PLGA-D/P NPs was dominated by clathrin-mediated endocytosis pathway $(p<0.001) .{ }^{29}$ The macropinocytosisdominated endocytosis pathway has been reported by several groups. Shim et al revealed that the positively charged DOTAP delivered DNA via macropinocytosis pathway

A
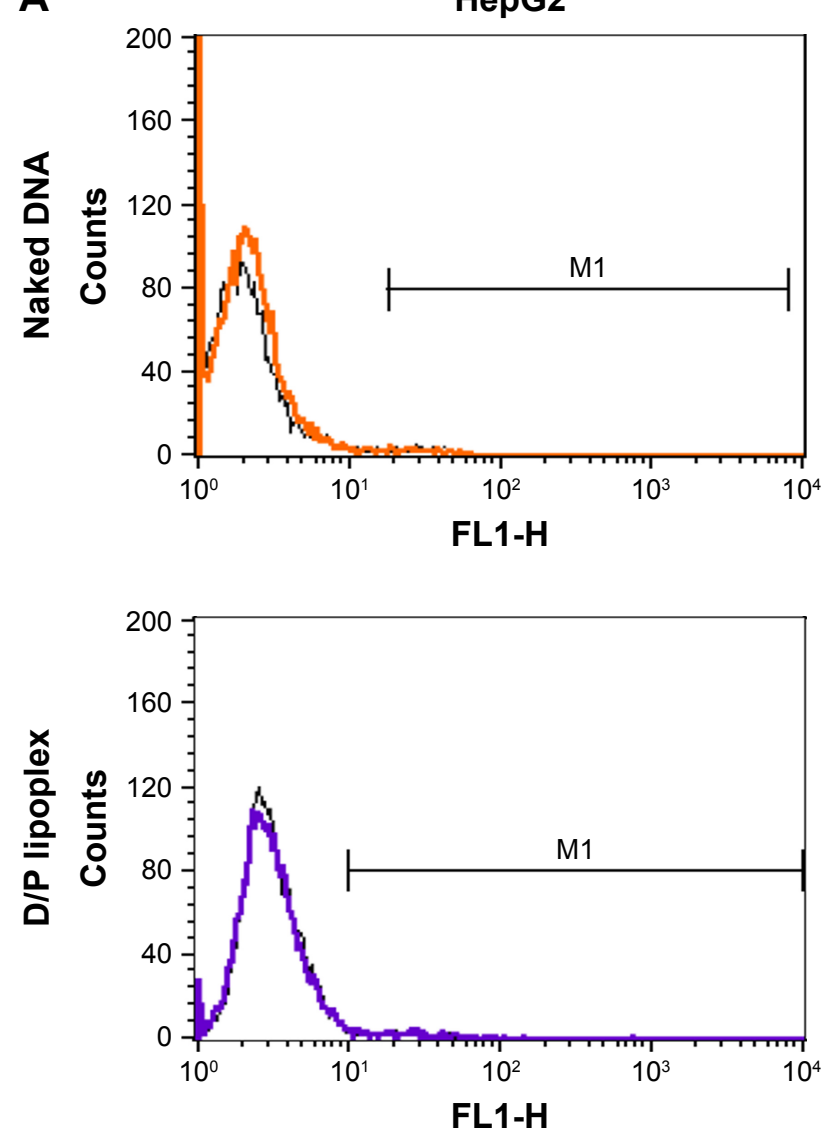

into cells. ${ }^{30}$ Greyner et al found that the uptake of HA was inhibited by amiloride in CD44 high-expressed B16-F10 melanoma cells, which indicated a macropinocytosisdominated endocytosis pathway. ${ }^{31}$

\section{Conclusion}

Two kinds of polysaccharide-conjugated PLGA-PEG NPs were synthesized and applied to encapsulate $\mathrm{D} / \mathrm{P}$ lipoplex as CD44 receptor targeting gene delivery nano-carriers. The negative-charged NPs prevented erythrocytes from agglutination and maintained particle size at $4^{\circ} \mathrm{C}$ for 28 days. The HA- and CD-PEG-PLGA NPs exhibited sustained release behavior wherein the DNA was completely released in pH 4.0 (500 U lipase) release medium within 24 hours but sustained release up to 72 hours in $\mathrm{pH} 7.4$ release medium. The CD-PEG-PLGA-D/P NPs had cellular viability similar to HA-PEG-PLGA-D/P NPs in U87 cells but higher than HA-PEG-PLGA-D/P NPs in HepG2 cells. The HA-PEGPLGA-D/P and CD-PEG-PLGA-D/P NPs expressed significantly higher transfection in CD44 high-expressed U87 than in CD44-negative HepG2. The high selectivity
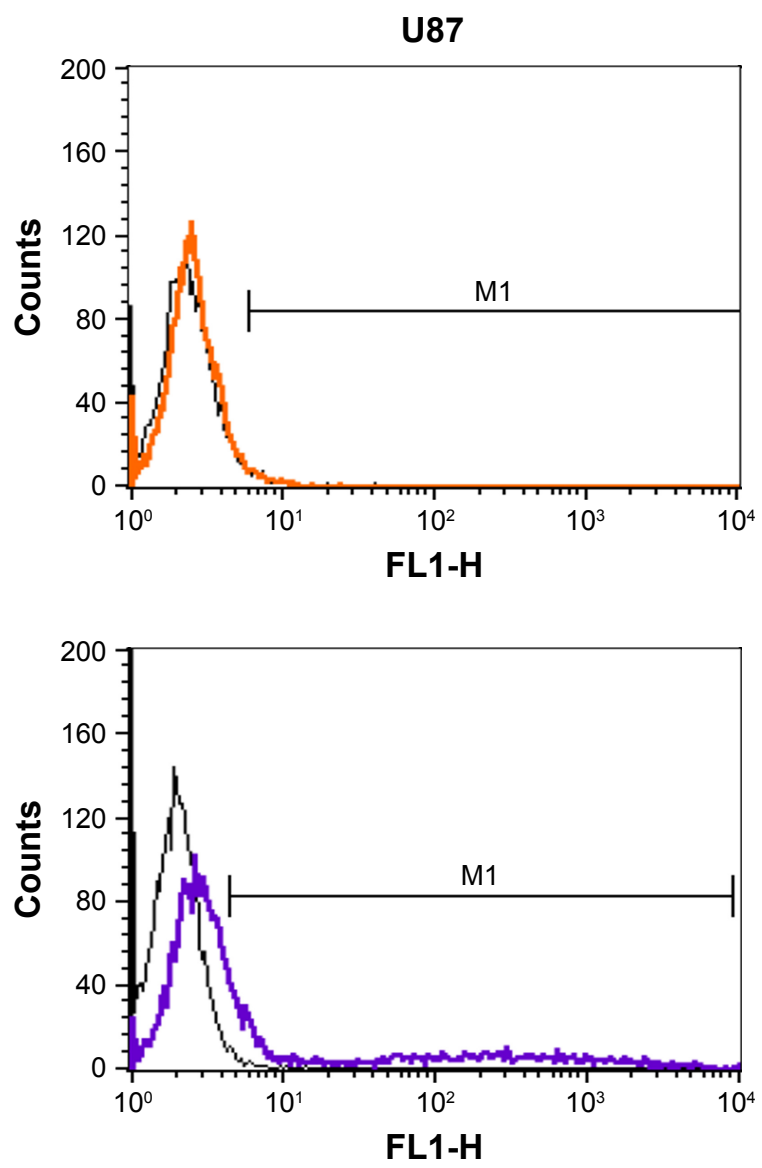

Figure 7 (Continued) 


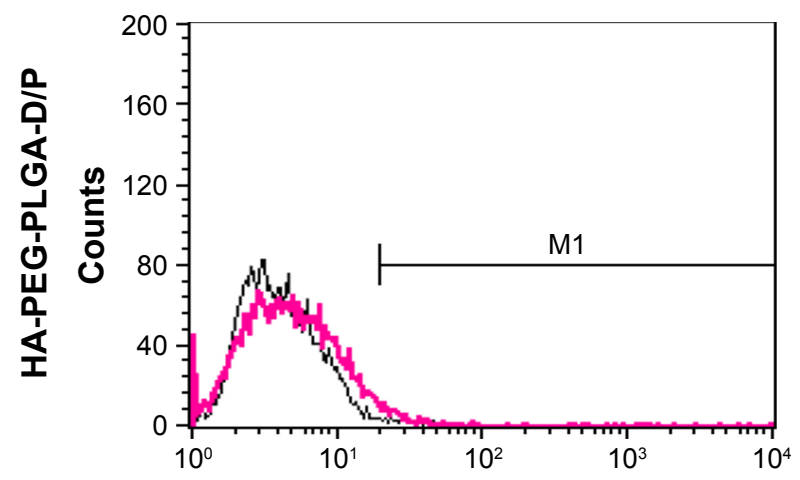

FL1-H
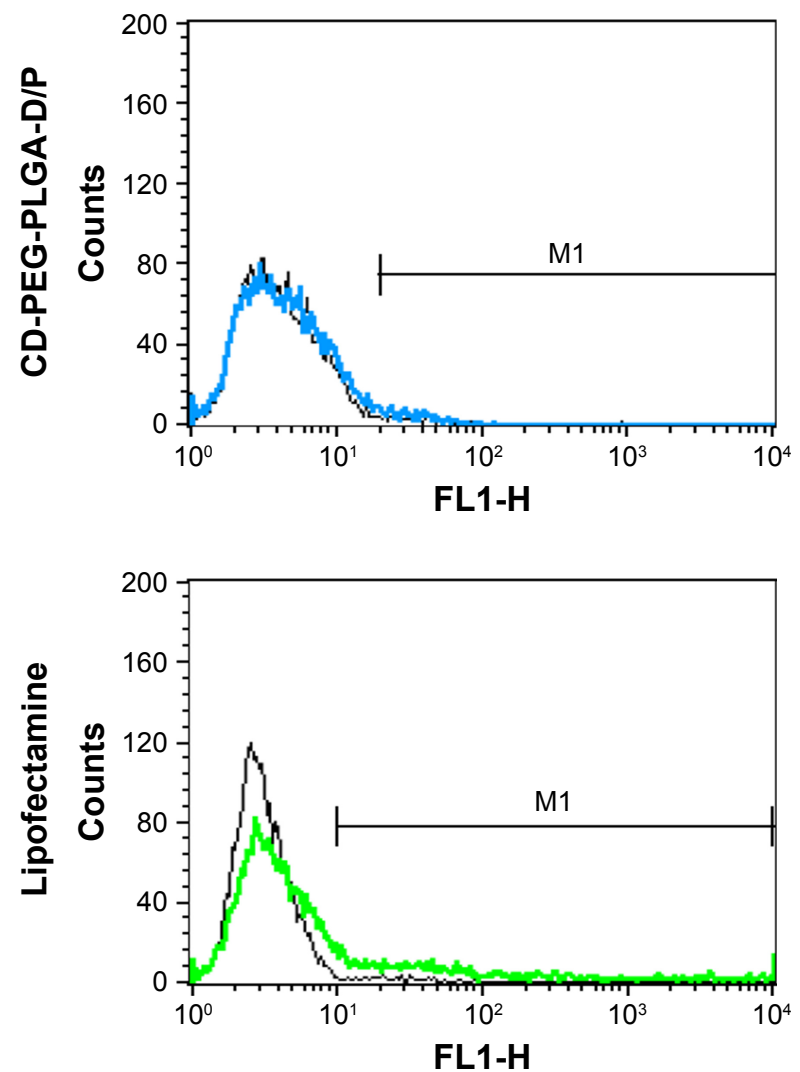
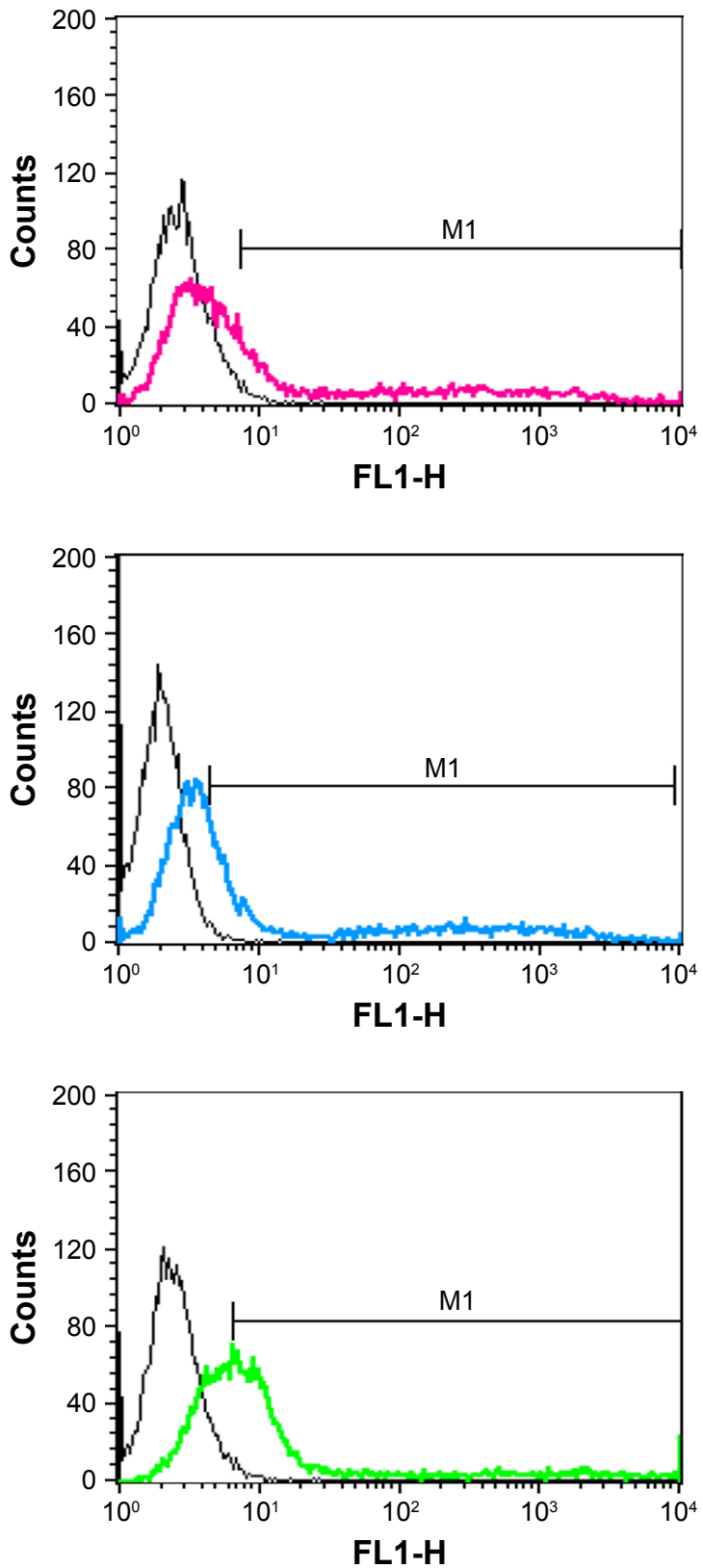

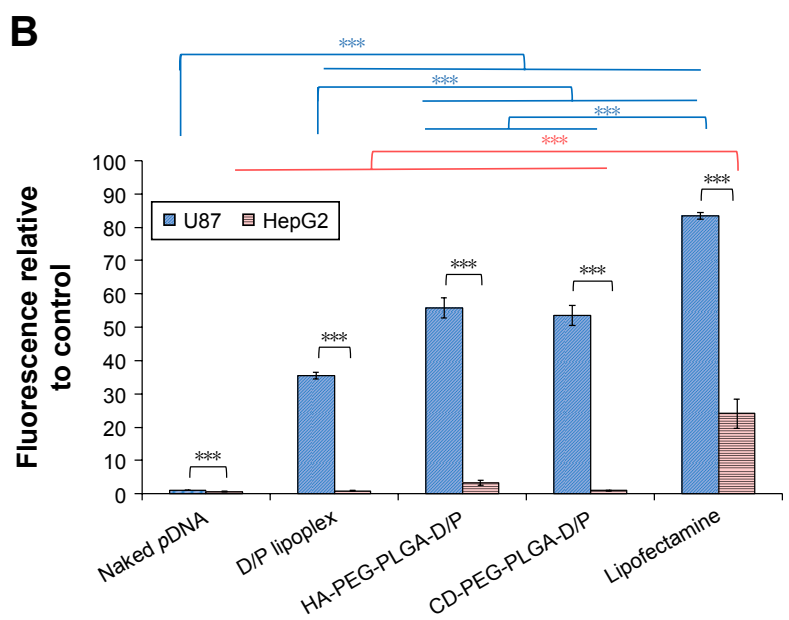

Figure 7 (Continued) 

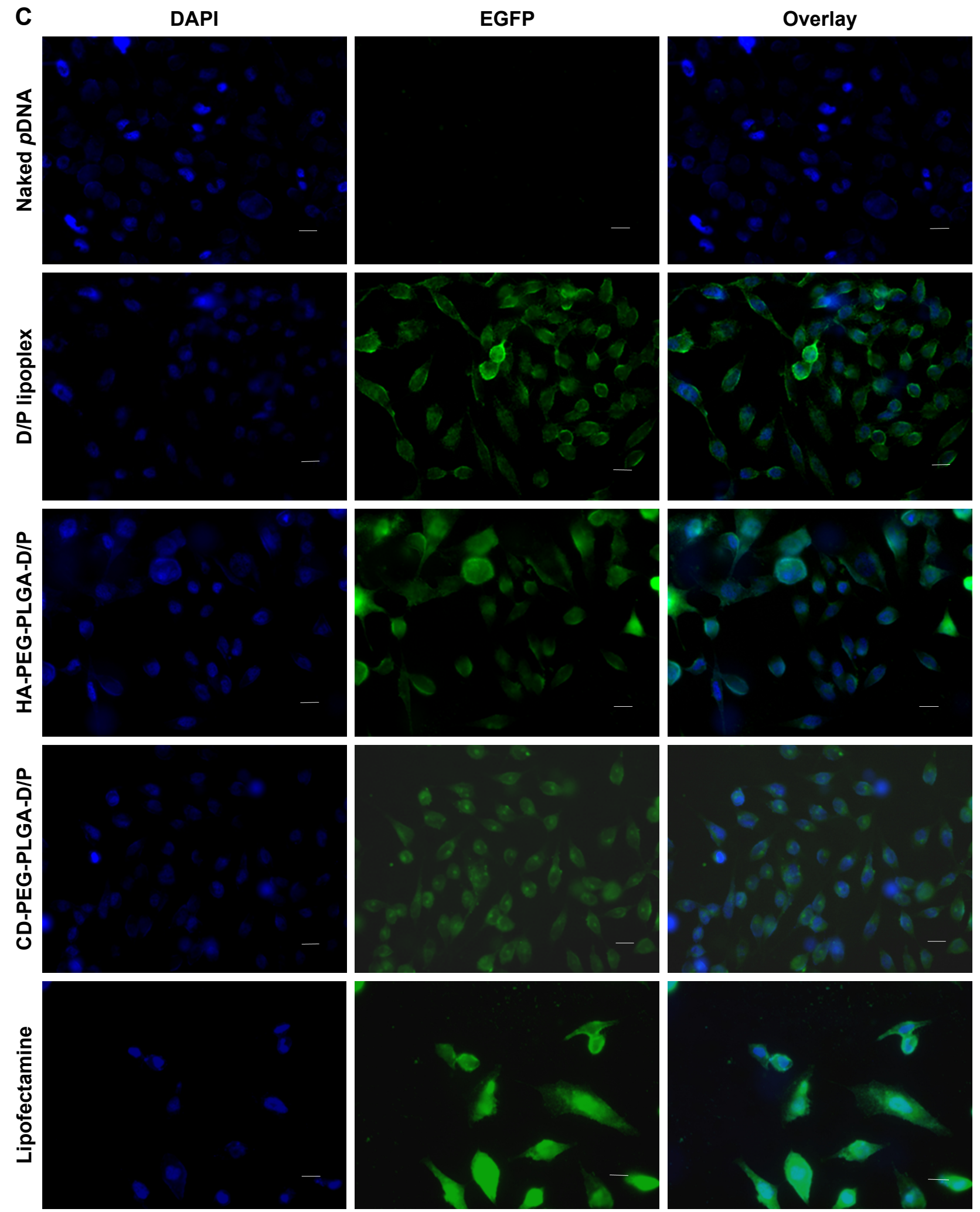

Figure 7 Transfection and confocal microscopic images of naked pDNA, D/P lipoplex, HA-PEG-PLGA-D/P NPs, CD-PEG-PLGA-D/P NPs, and lipofectamine.

Notes: (A) Flow cytometric analysis indicating intracellular fluorescence intensity in CD44-negative HepG2 cells and CD44-positive U87 cells (black lines indicate control and color lines indicate different formulations). (B) Transfection in terms of MFI values in CD44-positive U87 cells and CD44-negative HepG2 cells for 12 hours by flow cytometric analysis $(n=3, * * * p<0.001)$. (C) Confocal microscopic images of intracellular uptake in CD44-positive U87 cells (400x magnification).

Abbreviations: $\mathrm{CD}$, chondroitin sulfate; D/P, I,2-dioleoyl-3-trimethylammonium-propane/pDNA; HA, hyaluronic acid; MFI, mean fluorescence intensity; NPs, nanoparticles; PEG, poly(ethylene glycol); PLGA, poly(D,L-lactide-co-glycolide). 


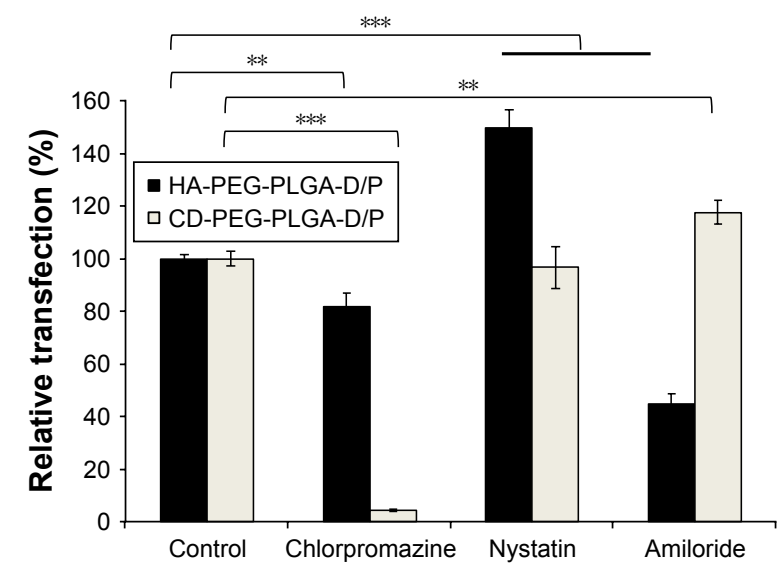

Figure 8 Effect of endocytosis inhibitors on transfection of D/P-loaded HA-PEGPLGA and CD-PEG-PLGA NPs in U87 cell line $(n=3$, **p $<0.01$, *** $p<0.001)$. Abbreviations: $C D$, chondroitin sulfate; D/P, I,2-dioleoyl-3-trimethylammoniumpropane/pDNA; HA, hyaluronic acid; NPs, nanoparticles; PEG, poly(ethylene glycol); PLGA, poly(D,L-lactide-co-glycolide).

to CD44-positive U87 cancer cells and low cytotoxicity in L929 normal cells assured the promising potential of CDPEG-PLGA NPs as gene delivery nano-carriers.

\section{Acknowledgments}

This work was supported by the Ministry of Science and Technology in Taiwan. The authors would like to acknowledge Miss Yu-Chen Lo for data analysis.

\section{Disclosure}

The authors report no conflicts of interest in this work.

\section{References}

1. Jones CH, Chen CK, Ravikrishnan A, Rane S, Pfeifer BA. Overcoming nonviral gene delivery barriers: perspective and future. Mol Pharm. 2013;10(11):4082-4098.

2. Alyafee YA, Alaamery M, Bawazeer S, et al. Preparation of anastrozole loaded PEG-PLA nanoparticles: evaluation of apoptotic response of breast cancer cell lines. Int J Nanomed. 2018;13:199-208.

3. Pamujula S, Hazari S, Bolden G, et al. Cellular delivery of PEGylated PLGA nanoparticles. J Pharm Pharmacol. 2012;64(1):61-67.

4. Ranganathan R, Madanmohan S, Kesavan A, et al. Nanomedicine: towards development of patient-friendly drug-delivery systems for oncological applications. Int J Nanomed. 2012;7:1043-1060.

5. Oliveira MF, Guimarães PP, Gomes AD, Suárez D, Sinisterra RD. Strategies to target tumors using nanodelivery systems based on biodegradable polymers, aspects of intellectual property, and market. J Chem Biol. 2013;6(1):7-23.

6. Liu CW, Lin WJ. Using doxorubicin and siRNA loaded heptapeptideconjugated nanoparticles to enhance chemosensitization in epidermal growth factor receptor high-expressed breast cancer cells. J Drug Target. 2013;21(8):776-786.

7. Liu CW, Lin WJ. Systemic co-delivery of doxorubicin and siRNA using nanoparticles conjugated with EGFR specific targeting peptide to enhance chemotherapy in ovarian tumor bearing mice. J Nanopart Res. 2013;15:1956-1969.

8. Sakhrani NM, Padh H. Organelle targeting: third level of drug targeting. Drug Des Devel Ther. 2013;7:585-599.
9. Jahangirian H, Lemraski EG, Webster TJ, Rafiee-Moghaddam R, Abdollahi Y. A review of drug delivery systems based on nanotechnology and green chemistry: green nanomedicine. Int J Nanomed. 2017; 12:2957-2978

10. Ramasamy T, Ruttala HB, Gupta B, et al. Smart chemistry-based nanosized drug delivery systems for systemic applications: a comprehensive review. J Control Release. 2017;258:226-253.

11. Ramasamy T, Tran TH, Choi JY, et al. Layer-by-layer coated lipidpolymer hybrid nanoparticles designed for use in anticancer drug delivery. Carbohydr Polym. 2014;102:653-661.

12. Ramasamy T, Haidar ZS, Tran TH, et al. Layer-by-layer assembly of liposomal nanoparticles with PEGylated polyelectrolytes enhances systemic delivery of multiple anticancer drugs. Acta Biomater. 2014; 10(12):5116-5127.

13. Ramasamy T, Ruttala HB, Choi JY, et al. Engineering of a lipidpolymer nanoarchitectural platform for highly effective combination therapy of doxorubicin and irinotecan. Chem Commun (Camb). 2015; 51(26):5758-5761.

14. Ramasamy T, Ruttala HB, Chitrapriya N, et al. Engineering of cell microenvironment-responsive polypeptide nanovehicle co-encapsulating a synergistic combination of small molecules for effective chemotherapy in solid tumors. Acta Biomater. 2017;48:131-143.

15. Williams K, Motiani K, Giridhar PV, Kasper S. CD44 integrates signaling in normal stem cell, cancer stem cell and (pre)metastatic niches. Exp Biol Med (Maywood). 2013;238(3):324-338.

16. Clemente N, Raineri D, Cappellano G, et al. Osteopontin bridging innate and adaptive immunity in autoimmune diseases. J Immunol Res. 2016;2016:7675437.

17. Dianzani C, Bellavista E, Liepe J, et al. Extracellular proteasomeosteopontin circuit regulates cell migration with implications in multiple sclerosis. Sci Rep. 2017;7:43718.

18. Dosio F, Arpicco S, Stella B, Fattal E. Hyaluronic acid for anticancer drug and nucleic acid delivery. Adv Drug Del Rev. 2016;97:204-236.

19. Mikami T, Kitagawa H. Biosynthesis and function of chondroitin sulfate. Biochim Biophys Acta. 2013;1830(10):4719-4733.

20. Liu YS, Chiu CC, Chen HY, Chen SH, Wang LF. Preparation of chondroitin sulfate-g-poly( $\varepsilon$-caprolactone) copolymers as a CD44-targeted vehicle for enhanced intracellular uptake. Mol Pharm. 2014;11(4): 1164-1175.

21. Gurav D, Varghese OP, Hamad OA, Nilsson B, Hilborna J, Oommen OP. Chondroitin sulfate coated gold nanoparticles: a new strategy to resolve multidrug resistance and thromboinflammation. Chem Commun (Camb). 2016;52(5):966-969.

22. Park JH, Cho HJ, Termsarasab U, et al. Interconnected hyaluronic acid derivative-based nanoparticles for anticancer drug delivery. Colloid Surf B. 2014;121:380-387.

23. Zhong Y, Goltsche K, Cheng L, et al. Hyaluronic acid-shelled acid-activatable paclitaxel prodrug micelles effectively target and treat CD44-overexpressing human breast tumor xenografts in vivo. Biomaterials. 2016;84:250-261.

24. Jing L, Shao S, Wang Y, Yang Y, Yue X, Dai Z. Hyaluronic acid modified hollow Prussian blue nanoparticles loading 10-hydroxycamptothecin for targeting thermochemotherapy of cancer. Theranostics. 2016;6(1):40-53.

25. Essendoubi M, Gobinet C, Reynaud R, Angiboust JF, Manfait M, Piot O. Human skin penetration of hyaluronic acid of different molecular weights as probed by Raman spectroscopy. Skin Res Technol. 2016;22(1):55-62.

26. Lin WJ, Lee WC, Shieh MJ. Hyaluronic acid conjugated micelles possessing CD44 targeting potential for gene delivery. Carbohyd Polym. 2017;155:101-108.

27. Lin WJ, Kao LT. Cytotoxic enhancement of hexapeptide-conjugated nanoparticles in epidermal growth factor receptor high-expressed cancer cells. Expert Opin Drug Del. 2014;11:1-14.

28. Liu CW, Lin WJ. Polymeric nanoparticles conjugate a novel heptapeptide as an epidermal growth factor receptor-active targeting ligand for doxorubicin. Int J Nanomed. 2012;7:4749-4767. 
29. Lo YL, Sung KH, Chiu CC, Wang LF. Chemically conjugating polyethylenimine with chondroitin sulfate to promote CD44-mediated endocytosis for gene delivery. Mol Pharm. 2013;10(2):664-676.

30. Shim G, Kim MG, Park JY, Oh YK. Application of cationic liposomes for delivery of nucleic acids. Asian J Pharm Sci. 2013;8:72-80.
31. Greyner HJ, Wiraszka T, Zhang LS, Petroll WM, Mummert ME. Inducible macropinocytosis of hyaluronan in B16-F10 melanoma cells. Matrix Biol. 2010;29(6):503-510.

\section{Publish your work in this journal}

The International Journal of Nanomedicine is an international, peerreviewed journal focusing on the application of nanotechnology in diagnostics, therapeutics, and drug delivery systems throughout the biomedical field. This journal is indexed on PubMed Central, MedLine, CAS, SciSearch $®$, Current Contents ${ }^{\circledR} /$ Clinical Medicine,
Journal Citation Reports/Science Edition, EMBase, Scopus and the Elsevier Bibliographic databases. The manuscript management system is completely online and includes a very quick and fair peer-review system, which is all easy to use. Visit http://www.dovepress.com/ testimonials.php to read real quotes from published authors.

Submit your manuscript here: http://www.dovepress.com/international-journal-of-nanomedicine-journal 